\title{
A revolução da informação: em busca do bem comum
}

\section{Philippe Quéau}

\section{Resumo}

A partir da globalização, o autor discute $o$ papel da sociedade da informação na construção de uma sociedade global voltada para o bem comum. Aborda principalmente a questão das telecomunicações e suas relações com o mercado, a necessidade de regulamentação para a área, a Internet, a promoção e o fortalecimento do domínio público, além de temas como competitividade e interesse público. O papel da Unesco na sociedade da informação e a busca por um sentido humanista para o processo de globalização também são discutidos.

\section{Palavras-chave}

Sociedade da informação; Globalização; Telecomunicações.

\section{A globalização é realmente global? "Glocalização". O bem comum}

Clichês retumbantes como "aldeia global" ou "sociedade global da informação" são enganosos. O conceito de "global" não é ele mesmo global, em outras palavras, a globalização não é "universal", não afeta a todos da mesma maneira. Precisamente como o conceito de "universalidade" não é "universal". Estou me referindo aqui a certos clamores vindos da Ásia manifestando suas preocupações em relação ao "espírito ocidental" da Declaração Universal dos Direitos Humanos e sustentando a idéia de que os "valores asiáticos" não foram ali adequadamente considerados e poderiam até mesmo estar em contradição com ela (por exemplo, a predominância confucionista da sociedade sobre os direitos da pessoa).

O conceito de "civilização global" é uma visão tendenciosa, um sonho sectário de uma minoria extremamente privilegiada ("os senhores globais"), um grupo muito pequeno dos habitantes deste planeta. A maioria esmagadora não vive, não compreende e menos ainda se beneficia da globalização, embora esteja de fato sofrendo suas conseqüências e seja direta ou indiretamente afetada por ela de modo efetivo e profundo. Esse é o resultado da "glocalização": o impacto local de causas globais escraviza as pessoas incapazes de entender as verdadeiras forças que estão em operação.

Assumimos um risco ao endossar visões parciais e concepções insuficientemente "universais", se ficarmos presos a um conceito de sociedade da informação que reflete a necessidade de deter a posse da informação. Podemos construir um entendimento realmente universal sobre o que está acontecendo? O "planeta azul" visto do satélite parece unido, mas frágil. O planeta Internet também parece unido, graças à "universalidade" do protocolo TCP/IP
(Transmission Control Protocol / Internet Protocol) ou do WWW (World Wide Web). Mas o consenso sobre a sociedade global é muito mais frágil. Quem fica com a maior parte? Quem lucra mais com a sociedade da informação?

Para o tecnocéticos, as novas tecnologias de comunicação e informação (NTCls) deveriam ser vistas como meras ferramentas. Essas ferramentas podem ser postas a serviço de uma vontade política, desde que esta exista. Mas, elas não trarão soluções já prontas e milagrosas para os problemas globais que infestam o fim deste século: instabilidades econômicas e financeiras, desigualdades sociais, desemprego crescente em países desenvolvidos, preocupações com o meio ambiente em todo o planeta, ampliando o abismo entre norte e sul e conduzindo, potencialmente, a perturbações políticas.

Para os tecno-otimistas, as NTCls não são apenas tecnologias. São sintomas de uma revolução mais profunda, indicadores úteis de uma avalanche cultural e mental que nos conduzirá, em última instância, a uma remodelação coletiva das verdades e valores básicos, como a noção de "trabalho" em um ambiente de produção automatizada, o conceito de "propriedade intelectual" em uma economia de idéias, a relevância do "Estado-nação" em um mundo globalizado, ou o significado de "interesse público" em um mercado livre e manipulado de forma invisível. O que está em jogo, de fato, é o aparecimento de uma nova civilização, por um lado certamente mais global e, presumivelmente, mais "virtual" ou "pós-industrial", mas, por outro lado, globalmente mais instável, cada vez mais eficiente para os superricos e insensível às necessidades dos pobres, excluídos da "eficiência" exigida pelo mercado livre. 
Céticos e otimistas têm razão, cada um a seu modo.

Vontade política é um recurso fundamental para resolver os problemas humanos. Até mesmo o escala do problema poderia ser maior do que a visão mediana dos líderes políticos. O que nós mais precisamos é uma visão política, uma visão realmente global capaz de subverter as agendas políticas de tendências chauvinistas, nacionalistas ou culturalmente limitadas. Este planeta está encolhendo rapidamente e, por isso, precisamos começar a pensar globalmente, e não apenas a partir das vantagens tecnológicas ou econômicas, mas também do ponto de vista político, cultural, social e ético. As perguntas fundamentais que devem ser feitas são:

- Qual será o impacto real da revolução da informação nos desequilíbrios globais do mundo? Agravará as desigualdades econômicas, culturais e sociais, ou tenderá a reduzi-las? Em outras palavras, a globalização agravará a globalização ou a humanizará?

- O que é "bem comum" nesse contexto global? É "bom" aquilo que é bom para o mercado livre e suas "mãos invisíveis"? É "bom" tudo o que é bom para as elites tecnológicas e econômicas das superpotências líderes ("os manipuladores de símbolos")? Ou existe um "bem comum mais elevado"?

\section{Um mundo, incontáveis tribos e muitos guetos}

A predominância da "convergência digital" afeta, agora, todos os aspectos das nossas sociedades. Esse fenômeno é ainda mais acelerado e facilitado pela tendência geral em direção à "globalização" econômica. De fato, as globalizações tecnológica e econômica estão interligadas e afetam todos os países, direta ou indiretamente.

Diferentes tipos de globalizações (financeira, econômica, tecnológica) florescem ao mesmo tempo e acompanham o desenvolvimento da sociedade "global" da informação, que, por sua vez, facilita a globalização. A globalização tecnológica está relacionada à distribuição espacial de idéias, métodos, tecnologias ou produtos. Não é uma universalização do "sentido", mas uma padronização de "meios". A globalização econômica assume a liderança em um contexto de laissez-faire de "desregulamentação", enquanto os temas políticos globais, como reduzir as desigualdades, favorecer a justiça social e a redistribuição econômica, ainda esperam ser tratados. Uma supraclasse global, que dispõe de capitais globais móveis, toma todas as principais decisões econômicas, sem muito controle e confrontando o poder de instituições políticas relativamente fracas, sem uma ação global efetiva e sem uma política global, sem uma visão global adequada ao nosso tempo.

As "globalizações" da cultura, da sociedade, da política e da ética permanecem ainda na retaguarda. As globalizações se traduzem em "relativismo" político, ético, cultural. Em vez de promover valores universais, e a universalidade como um valor, a globalização parece encorajar o relativismo. O Estadonação vê seu poder, legitimidade e campo de ação seriamente abalados pelos atores e processos transnacionais: corporações multinacionais, o fluxo das finanças e da informação, fenômenos ambientais, máfias, migrações. Freqüentemente, a regulamentação regional é insuficiente. As Nações Unidas estão muito fracas.

O enfraquecimento do Estado diminui sua capacidade para deter a escalada da pobreza, a exclusão e o desemprego, assim como para trabalhar para a melhoria da educação e dos sistemas de saúde. O "contrato social" em cada sociedade está ameaçado por uma globalização cega e sem fronteiras, sem nenhum interesse por projetos coletivos. Confrontado com o poder e a influência do mercado, o Estado-nação está debilitado e perde o seu sentido simbólico, os mesmos valores que tornaram sua existência possível e significante.

Existe a possibilidade de que, na ausência de um poder político global e efetivo, que seja capaz de redistribuir as riquezas mundiais e de garantir a justiça e o significado de "bem comum", a sociedade global da informação não será igualmente vantajosa para todos os países. Sabemos que em quase todas as sociedades, as necessidades e as preferências dos ricos e poderosos geralmente são mais respeitadas e refletidas nas metas e prioridades oficiais. A so- ciedade da informação, por si, não mudará esse estado de coisas. Ao contrário, poderia simplesmente agravá-lo. Pelo menos, é um ótimo ponto para debater. Enquanto é possível observar uma certa ampliação do acesso às NTCls, um exame mais detalhado mostra que tal acesso está, na verdade, reservado para os que já são privilegiados.

O Relatório sobre o Desenvolvimento da Telecomunicação Mundial de 1998, publicado em março desse ano pela União Internacional de Telecomunicação, afirma: "Ainda restam vastas concentrações humanas sem acesso aos serviços básicos de telecomunicações. É difícil acreditar que isso se deva à escassez de capital: a indústria de telecomunicações teve seu ano mais lucrativo em 1996, como jamais visto. O déficit de fornecimento também não é um argumento razoável para a falta de acesso. O maior inimigo da melhoria do acesso, hoje, parece ser a complacência. Há uma tendência em acreditar que uma indústria lucrativa com fontes de abastecimento em expansão resolverá o problema por si só”.

Em nossa opinião, não resolverá. Em outras palavras, ainda haverá vencedores e perdedores na emergente ordem da sociedade da informação. E a distância entre eles provavelmente se alargará. O problema não será resolvido milagrosamente pelas virtudes imanentes da indústria. Há algum modo de usar as NTCls para unir os extremos assustadores em que se encontram ricos e pobres? De que maneira as NTCls podem ajudar os quatro bilhões de pessoas que vivem com menos de $\$ 2$ por dia? Essa não é apenas uma questão de justiça global. Também está no interesse objetivo dos ricos. O que gostaríamos de salientar é que até mesmo os vencedores serão perdedores, em última instância, se deixarem tal distância aumentar. Por duas razões: 1a) eles sofrerão do desassossego político e social ao qual o espetáculo mundial desse abismo crescente inevitavelmente induzirá; 2a) a elevação dos padrões de vida da população mundial, afinal, irá beneficiar a todos, exceto, é claro, àqueles que presentemente se favorecem da exploração das desigualdades globais. 
O que deveríamos fazer para evitar as discrepâncias e as desigualdades que surgirão desses diferentes tipos de globalização e da distribuição irregular dos seus efeitos entre as nações? Como poderíamos contribuir para a elaboração de um conceito de "bem comum", de "interesse público" da humanidade, no contexto da sociedade da informação em sua fase mais globalizada?

\section{Há um piloto no avião global?}

Como representante do povo e guardião dos valores democráticos, o Estado tem o direito e a responsabilidade de ajudar a integrar o ciberespaço e a sociedade. Mas quem garante a integração do ciberespaço e da sociedade global? Nosso planeta como um todo não é ainda "democraticamente" representado, exceto talvez por organizações internacionais como as Nações Unidas, que notoriamente sofrem da falta de meios financeiros e políticos para intervir efetivamente nos temas globais centrais.

O ciberespaço não é uma terra de ninguém, não mais do que os paraísos fiscais são. Se os governos do mundo decidissem unir esforços no sentido de suprimir todas as possibilidades de evasão de impostos ou de tráfico ilegal de moeda, poderiam muito bem impor sua vontade aos paraísos fiscais e de lavagem de dinheiro. Similarmente, se em algum momento no futuro, os governos do mundo decidissem impor uma base rigorosa de uma futura ciberlei, isso poderia muito bem ser feito. Afinal de contas, computadores e redes ainda são objetos essencialmente materiais que são necessários ao ciberespaço imaterial. E a polícia e a justiça podem muito bem atuar nos domínios concretos do ciberespaço.

Padrões tecnológicos e questões de privacidade, por exemplo, são muito importantes para serem confiados exclusivamente ao mercado. Empresas de software competidoras têm pouco interesse em preservar os padrões abertos que são essenciais para o completo funcionamento de uma rede interativa. Os mercados encorajam a inovação, mas não asseguram necessariamente o interesse público. Os governos poderiam decidir-se a encorajar e apoiar o desenvolvimento de softwares de domínio pú- blico e freewares ${ }^{*}$ (como LINUX e Apache). Essa meta poderia tornar-se absolutamente vital em poucos anos, quando se evidenciará a importância de equipar as escolas de todo o mundo com recursos básicos de informática. $\mathrm{O}$ setor do software poderia muito bem pertencer ao domínio público mundial.

As questões de privacidade também têm importância estratégica. Os interesses comerciais são mantidos em low profile, isto é, não são declarados ou evidenciados, e livres para, segundo seu próprio arbítrio, explorar os recursos poderosos da garimpagem de dados para pesquisa de marketing ou para revender a informação aos agentes de dados (data brokers) e à indústria de "serviço de referência pessoal". Não há interesse em questões polêmicas como: Os direitos sobre a informação pessoal deveriam pertencer às pessoas envolvidas ou aos garimpeiros de dados? Que nível de anonimato e proteção da privacidade é desejável? Esse é essencialmente um problema filosófico e político.

Os Estados Unidos e a União Européia diferem um pouco quanto ao fluxo transnacional de dados. Os Estados Unidos acusam a diretiva do Parlamento da União Européia sobre a proteção de indivíduos com respeito ao processamento de dados pessoais e sobre o livre trânsito de tais dados (outubro de 1995) de ser uma barreira comercial não-tarifada para o livre comércio. Na realidade, o Artigo 25 estabelece que "a transferência, para um terceiro país, de dados pessoais que estão em processamento ou são objeto de processamento depois da transferência pode ocorrer somente se [...] o terceiro país em questão assegurar um nível adequado de proteção". Considerando que resta comprovar se há qualquer nível adequado de proteção nos Estados Unidos, a pergunta ainda está pendente: De quem é a última palavra? Do mercado livre ou do cidadão global consciente de sua privacidade?

\footnotetext{
* Freeware é um arquivo (programa, texto, imagem ou som) distribuído gratuitamente, e cujo uso é livre, desde que não seja para fins comerciais. (Nota da Tradutora).
}

\section{Mercado versus interesse público. Necessidade de regulamentação}

O mercado não está preocupado com a redistribuição social. Questões sociais importantes (como educação e saúde básicas ou a manutenção da paz social ou até mesmo da paz internacional) são transferidas para a esfera "política". O mercado precisa de paz e também de uma população educada para desempenhar suas próprias funções. Mas paz e educação devem ser cultivadas e, também, pagas. Por quem? Não há certeza de que a paz internacional, por exemplo, receba toda a atenção que deveria ser conferida a ela, prioritariamente.

A desregulamentação e a globalização têm um gosto de mercado livre, sem restrições. Precisamos, contudo, de uma re-regulamentação em um nível mais alto. Precisamos de um controle global, isto é, um governo global com uma moeda global e uma fiscalização global (como o famoso Imposto de Tobin sobre todas as transações financeiras, proposto pelo Prêmio Nobel, James Tobin). Por que não imaginar um imposto global para as telecomunicações ou um imposto de "energia global" para ajudar a reduzir os desequilíbrios do acesso à informação e lutar pelas questões ecológicas globais?

O mercado está assentado na competição. Conseqüentemente, os mais fortes emergem, com um efeito não-linear: o declínio dos competidores mais fracos (provocado pelo mercado livre) cria monopólios ou oligopólios (que estão em oposição ao interesse público). Os problemas com os monopólios de software (Microsoft/Netscape, Java/Active X) são bons exemplos. Eis por que os legisladores ainda têm um papel a desempenhar, mesmo em um "mercado livre".

Qual deveria ser o novo paradigma do "acesso universal"? Baseado no acesso físico? Deveria incluir acesso ao "conteúdo", por exemplo, dos dados de domínio público? Qual deveria ser o nível mínimo para o serviço aos usuários? É possível calcular o custo dos compromissos para a realização dos serviços públicos de um modo significativo? Quais deveriam ser os "direitos do consumidor"? Esses direitos estão interferindo com os "direitos do cidadão", se forem limitados pelo interesse do "mercado"? 
Os legisladores também são necessários para uma distribuição justa de recursos (acesso a dados, disponibilidade de espectro de radiofreqüência, valoração do preço do espectro, leilão de freqüências). O nível de demanda por espectro provavelmente supera os recursos de freqüência disponíveis atualmente. Como estabelecer uma política de preços para esse recurso público?

\section{Desregulamentação não significa necessariamente mais competição}

Uma das principais falhas da regulamentação em telecomunicações pode ser assim resumida: o legislador nunca teve independência para tomar decisões profissionais por causa da influência indevida de políticos, ministérios politicamente dirigidos, ou dos monopólios regulamentados. Os monopólios privados de operadoras em telecomunicações subjugam os legisladores e, freqüentemente, os impedem de aplicar as normas efetivas de proteção ao consumidor ou de eficiência econômica.

Nos últimos anos, os órgãos reguladores de telecomunicações nos Estados Unidos, Canadá e Reino Unido têm fracassado, de forma notável, em conter o comportamento anticompetitivo das operadoras dominantes e promover uma efetiva competição do mercado. Por exemplo, a Federal Communications Commission (FCC), dos Estados Unidos, admitiu sua inabilidade para regular a AT\&T no momento da sua alienação. Hoje, em quase todos os países, tratando-se das principais questões sobre regulamentação, os grandes atores estão se dirigindo diretamente aos políticos.

Assim, seguindo a legislação de 1996 sobre telecomunicações nos Estados Unidos, que liberaliza todo o mercado da área, as primeiras fusões envolveram o holding regional Bell (RBHCs) em um movimento defensivo para fortalecer suas posições monopolistas em mercados locais de telecomunicações.

As operadoras públicas de telecomunicações (OPTs) se colocam no caminho do comércio e freqüentemente representam um obstáculo que pode retardar ou até mesmo impedir melhorias, especialmente o desenvolvimento de novos serviços. As OPTs são fortemente estimuladas a usar seu poder de monopó- lio colocando-se no topo da hierarquia das telecomunicações para capturar o máximo possível da eficiência e dos benefícios importantes que estão sendo criados nos setores de equipamentos e de serviços. Se os planejadores de políticas e os legisladores adotarem uma posição de isenção ou de laissezfaire sobre a questão da competição, a maioria dos consumidores de telecomunicações corre o risco de ter acesso a um mercado com uma política de competição, mas com poucas opções competitivas reais.

\section{Dividindo os custos das ligações internacionais. $O$ caso da Internet}

As tarifas das telecomunicações internacionais têm um impacto significativo nos rendimentos e no crescimento das telecomunicações nos países em desenvolvimento. A completa liberalização das telecomunicações em conjunto com outros fatores (o advento do callback *, a telefonia da Internet) suscitam sérias preocupações em relação ao antigo sistema de dividir o custo de uma ligação internacional entre os países. O tradicional sistema de tarifas, que tem sido utilizado por muitos anos, é um método de arrecadação compartilhada estabelecido por meio de negociações bilaterais. As transmissoras de telecomunicações negociam entre si o preço para operar um minuto de serviço telefônico internacional. A tarifa normalmente é dividida entre as transmissoras de origem (50\%) e de destino (50\%), no caso de uma conexão direta entre elas. Para as conexões indiretas, há também uma taxa de trânsito fixa.

Uma vez que, normalmente, existe um desequilíbrio, a operadora com o maior volume de minutos paga um ajuste líquido para o operador com menos minutos. Como os volumes de trânsito têm aumentado durante os anos, as administrações pagantes têm exercido forte pressão para reduzir a tarifa de ajuste ao nível dos custos reais para as liga-

\footnotetext{
* Serviço que permite ao usuário efetuar ligações internacionais, através de operadoras, com tarifas reduzidas. O usuário disca um código de acesso pessoal e, após escutar o primeiro toque, desliga a chamada. Imediatamente, ele recebe uma ligação de retorno com um novo sinal de discagem. A partir daí, disca para o número que deseja. (Nota da Tradutora).
}

ções de destino. Muitas nações da Ásia e do Pacífico são países em desenvolvimento e são, também, os que recebem os ajustes líquidos. Geralmente, o custo da infra-estrutura de telecomunicações nos países em desenvolvimento é mais alto porque suas economias não se comparam com a dos países avançados, que têm a vantagem da indústria local e das grandes economias de escala. Esses países podem se sentir inclinados a resistir aos esforços dos países de origem do trânsito em exercer pressões para baixar as tarifas.

Práticas como callback podem aumentar as pressões sobre o sistema. A operadora de callback atrai consumidores de outras operadoras que cobram tarifas mais altas. Isso freqüentemente resulta em perda de negócios para as operadoras dos países em desenvolvimento. A recente norma da FCC objetiva reduzir drasticamente as tarifas de ajuste. Muitos países se opõem à essa norma, sentindo que o seu único propósito é beneficiar as operadoras dos Estados Unidos às custas dos países em desenvolvimento. A cobrança baseada nos custos não é fácil de implementar, e implica um reequilíbrio entre tarifas locais, de longa distância doméstica e internacional. Em efeito, esse acordo internacional de redução conduziria, em última análise, a uma diminuição da renda dos países em desenvolvimento e a viabilidade das telecomunicações, já ameaçadas pela queda contínua na sua arrecadação de chamadas devido à proliferação dos serviços de callback. Além disso, as estruturas convencionais de telecomunicações serão suplantadas pela comunicação por voz na Internet ou nas redes virtuais privadas.

Esse é um problema global, mas focado principalmente nas vantagens dos Estados Unidos e dos países de origem das chamadas. A FCC já tomou medidas unilaterais, como em julho de 1997. Entretanto, o crescimento da rede internacional será ineficiente, se as instalações não forem distribuídas uniformemente em relação aos padrões de uso.

O princípio da tarifa de destino está sendo examinado. As operadoras de telecomunicações poderiam estabelecer uma tarifa padronizada e transparente para o trânsito de entrada baseada em custos e outros fatores (como taxa de 
juros sobre empréstimos de desenvolvimento, subsídios...). Essa tarifa seria aplicável independentemente da origem das chamadas, eliminando a necessidade de acordos bilaterais.

O caso da Internet é bem ilustrativo desses acentuados desequilíbrios. A Internet serve como um banco de dados em que os usuários localizados fora dos Estados Unidos têm acesso aos web sites desse país, obtendo informações. O trânsito das ligações é quase todo em um só sentido. Conseqüentemente, as transmissoras dos Estados Unidos insistiram para que as transmissoras localizadas fora do país pagassem pela conexão completa, em vez dos acordos tradicionais em que cada transmissora pagaria a metade da sua própria conexão. A Internet, hoje, está além da função de fornecer informações, sendo cada vez mais usada como uma outra plataforma para a comunicação internacional (trânsito de mão dupla), por exemplo, o correio eletrônico, telefonia da Internet, comércio eletrônico.

A permanência do acordo de pagamento assimétrico existente já não pode ser justificada. É injusto para as transmissoras localizadas fora dos Estados Unidos e especialmente para os usuários, porque os usuários norte-americanos não estão pagando por seu acesso internacional à Internet. Os rendimentos dos serviços da Internet em todo o mundo são enviados às operadoras dos Estados Unidos. Os proprietários dessas operadoras e dos bancos de dados estão obtendo completa vantagem do fluxo de trânsito para dentro do país.

\section{Política de preços e regulamentação para as telecomunicações}

É muito difícil calcular os custos relevantes de um sistema complexo de redes de telecomunicação. O representante Barrett, da FCC, declarou: "A determinação de custos se tornará cada vez mais difícil e sem sentido no futuro... Uma vez que as transmissoras locais de permutação estão transportando broadband ${ }^{*}$ vídeo ao lado de seus

\footnotetext{
* Broadband, conhecida como banda larga, é uma técnica que permite a transmissão de um grande volume de informações, incluindo voz, dados e vídeo, através de longas distâncias e usando o mesmo cabo. (Nota da Tradutora).
}

serviços de voz e que a telefonia sem fio é extensivamente usada para acesso local, a determinação de custos será um pesadelo com pouco sentido... Para tomar um exemplo simples, consideremos como o custo de uma conexão local será determinado se essa conexão for usada para transmitir voz, broadband e vídeo simultaneamente".

Um exemplo concreto: No Japão, até recentemente, a NTT cobrou da sua própria divisão de chamadas de longa distância $¥ 3.7$ (quatro centavos de dólar americano) por ligação (o que constituiu cerca de $4 \%$ da receita daquela divisão), cobrando de seus rivais mais de 10 vezes esse valor pelas mesmas ligações de longa distância (aproximadamente $¥$ 42 por chamada), embolsando perto de $45 \%$ dos rendimentos de seus competidores. Essa política de preços é apontada como o principal fator que impediu o desenvolvimento da competitividade no Japão (Xavier ${ }^{1}$ ).

O que gostaríamos de acentuar é que não há princípios de fixação de tarifas universalmente "corretos". Uma política de preços é um meio de alcançar os objetivos pretendidos. Portanto, a pergunta é: Quem deveria decidir esses objetivos: o mercado ou o órgão regulador - que supostamente garantiria o "interesse público"?

\section{Competição "formal" versus competição “justa” : o caso da Coréia}

Em 1990, o Ministério da Informação e Comunicação (MIC) da Coréia decidiu introduzir a competição no mercado de serviços de telecomunicação internacional, na esperança de fortalecer a competitividade da indústria de telecomunicações coreana. Em 1991, a Dacom, que vinha atuando no campo da comunicação de dados de forma monopolista, entrou no mercado, até então dominado pela Coréia Telecom.

Porém, a competição nos serviços de telefonia internacional não funcionou como esperado. A competição não conseguiu aumentar a demanda, apesar da propaganda e dos novos serviços. A regulamentação direta de preços do MIC impediu as transmissoras de competir em preços e induziu a uma conspiração entre elas, inviabilizando o aumen- to de consumidores. A competição restrita de preços encorajou as transmissoras a se engajarem em uma competição publicitária anormal, e desestimulou investimentos mais eficientes. Conscientes de que o preço não era determinado pelas interações competitivas entre elas, mas pela instância reguladora, as transmissoras não precisaram dirigir sua atenção aos consumidores.

Em suma, essas experiências competitivas malogradas podem ser atribuídas ao ambiente de competição pobre. Foi ingênuo esperar que a competição surgiria automaticamente ao permitir a entrada de uma empresa em um mercado, sem preparar o ambiente para uma competição efetiva (que deveria ter sido o papel do MIC). Na Coréia, contar com um competidor a mais conduziu somente uma conspiração tácita contra a intenção original de promover a competição. Essa experiência competitiva bastante indesejável decorreu de um conceito peculiar de competição, ou seja, a "competição formal". O MIC interveio ativamente no processo de competição que diminuiu a rivalidade entre as transmissoras. O Ministério estabeleceu um sistema de competição controlado, mas não efetivo.

É essencial que o conceito de competição formal seja substituído pelo conceito de "competição justa". A regulamentação da competição justa força a supressão dos incentivos concedidos aos agentes para utilizar suas vantagens e praticar atitudes anticompetitivas, como política de preços predatórios, acordos de acesso desiguais e posse exclusiva de informação. Segundo o conceito de "competição justa", o legislador não deveria julgar, controlar ou modificar o grau da competição. Em vez disso, o legislador deveria limitar-se à preparação do ambiente para a competição ativa.

A competição é o mecanismo mais poderoso para maximizar os benefícios aos consumidores e limitar o poder do monopólio. O cerne da competição não é o número de competidores, mas a rivalidade entre eles. Os instrumentos do legislador devem ser dirigidos para facilitar a rivalidade. Infelizmente, o governo coreano não reconheceu esse ponto importante e se comportou de um modo tradicional para controlar o monopólio, suprimindo a rivalidade. Os legisladores 
nos países em desenvolvimento deveriam ter em mente que a competição controlada não é melhor que o monopólio. Eles deveriam limitar-se a proteger a competição justa, com vistas ao "interesse público".

\section{Público e privado. A importância crucial do domínio público}

A principal preocupação da mídia privada é ganhar dinheiro. A principal tarefa da mídia orientada para o interesse público é promover o desenvolvimento político e cultural, nos níveis nacional e internacional. Metas abertas como "interesse público" ou "desenvolvimento cultural" são muito difíceis de medir. Interesse público é um assunto muito mais complexo de compreender do que interesse privado. É mais abstrato e, em essência, mais conflitante para definir. Generalizou-se entre todas as pessoas, de modo que ninguém em particular parece direta e pessoalmente envolvido ou ansioso para atacar esse tipo de problema vago e global, freqüentemente abandonado a burocracias anônimas. Esse problema é um outro aspecto da "tragédia dos comuns". Quando se espera que todo o mundo esteja cuidando do que é "comum" a todos, ninguém sente que é imprescindível e fundamental fazê-lo. Alguém mais se encarregará disso... E interesses comprometidos tiram proveito desse desinteresse público pelo bem público no sentido de sensibilizar aqueles que tomam as decisões para as suas próprias necessidades específicas. Quanto mais os problemas ganham dimensão global e abstrata, mais o bem público parece permanecer desconsiderado, e mais os interesses privados tornam-se eficientes e ativos em tirar a sua própria fatia de lucro do bolo público.

Esse mecanismo universal não será detido pela revolução da informação. Pelo contrário, será agravado. Precisamos de um entendimento profundo sobre o que de fato é o "bem comum" na era da informação. É "acesso universal", por exemplo? Ou algo mais abstrato como igualdade de oportunidades para todos na sociedade da informação? Um bom começo para refletir sobre o "bem público" concretamente é a questão do "domínio público".
No auge da "bolha econômica" no Japão, surgiu uma proposta esdrúxula para devolver todas as terras ao imperador. Essa idéia não era nova. O conceito de "terra comum" existiu há muito tempo, no período feudal na Europa e, mesmo mais recentemente, foi classificado sob a categoria política de res publica. Agora, a bolha esvaziou-se. Mas o conceito de "domínio público" permanece válido. A zona marítima internacional, o espaço sideral ou o genoma humano pertencem ao domínio público ou à herança inalienável da humanidade.

Em nossa era globalizada, é de importância vital e estratégica reconhecer, promover e fortalecer o domínio público global, seja físico (como o espectro de rádio), ou cultural e informacional (como as obras-primas do passado ou a informação produzida com capitais públicos). O espectro hertziano pertence ao domínio público. Assim, o público deveria beneficiar-se do seu uso. O recente espectro digital concedido para as empresas de radiodifusão acentua o uso ineficiente e tendencioso dos recursos públicos. O cidadão deveria beneficiarse e lucrar com o uso das freqüências públicas e deveria reter uma faixa do espectro para uso educativo, cultural e de acesso público. Deveríamos exigir mais do uso privado da propriedade pública.

O mesmo problema se repete com os dados de domínio público. Obras-primas do passado glorioso, armazenadas em bibliotecas e museus públicos, não pertencem aos seus curadores, mas ao público de uma nação particular e, também, à humanidade. Se cada nação decidisse devolver ao seu povo livre acesso à sua própria memória, então, não apenas todos teriam acesso aos seus próprios tesouros culturais, mas também à herança cultural de todas as outras nações.

Uma regulamentação global é realmente necessária. Mas, acima de tudo, precisamos encontrar um novo significado para a nossa ação coletiva. Precisamos formular uma visão mais abrangente e mais sábia do que estamos vivenciando como cidadãos da nossa sociedade global. Precisamos de novas ferramentas mentais.

\section{Novas ferramentas cognitivas para uma cidadania global}

Excesso de dados é apenas ruído. A informação não é conhecimento, nem mesmo sabedoria. Precisamos do sentido da informação, mais do que dos seus meios. Precisamos ainda mais de sabedoria. A proliferação da informação não somará um minuto ao dia de um ser humano. Com o excesso de informação, não estamos fazendo necessariamente nada melhor que antes. Pelo contrário, podemos simplesmente perder o senso de realidade e o toque humano. A abundância de informação é um sério desafio, exigindo disciplina, distanciamento e ceticismo. Precisaremos de habilidades cognitivas de percepção, razão, julgamento e bom senso.

Há uma atrofia do sensus communis (o bom senso). O sensus communis é o que pode nos dar o senso do "bem comum". Esse sexto sentido é, antes de tudo, o senso político, o senso de julgamento. Julgar sempre implica uma forma de distanciamento, isenção, capacidade de abstração dos eventos e fatos. Julgar também implica uma atenção para a pluralidade, para a diversidade. Implica um modo de pensar mais amplo e iluminado, resultado da comparação do seu próprio julgamento com o de outros. Implica a habilidade de colocar-se no lugar dos outros, entender outras posições, outros pontos de vista. Implica uma capacidade para distanciar-se de si mesmo. É uma aptidão para pensar como indivíduo no interesse da comunidade.

Em um mundo dirigido pelo fluxo de informação, as interfaces - e os códigos subjacentes - que tornam a informação visível estão se transformando em forças sociais enormemente poderosas. Entender suas forças e limitações e mesmo participar na criação de ferramentas melhores deveria ser uma parte importante na vida de um cidadão consciente. Essas ferramentas afetam nossas vidas tanto quanto as leis, e deveríamos sujeitá-las a um escrutínio semelhante.

Precisamos entender melhor os princípios subjacentes das ferramentas cognitivas (modelos de simulação, modelos conceituais e de computação, esquemas cognitivos, estatísticas) que 
usamos cada vez mais, conscientemente ou não. Um novo iluminismo "cognitivo" é necessário. Estamos ainda na ldade das Trevas do governo global e nem mesmo sabemos quão longe ainda estamos de adquirir ferramentas cognitivas mínimas para lidar com os problemas da globalização.

Construir escolas não será o bastante. Precisamos saber em que tipo de cidadão queremos que nossas crianças se transformem. Queremos que nossas crianças cresçam felizes e sábias, não apenas como técnicos, com a cabeça cheia de dados desnecessários e voláteis. Não queremos que nossas crianças sejam treinadas para estar a serviço de uma esfera econômico-técnica destituída de qualquer visão humanitária verdadeira. Em resumo, precisamos de uma abordagem humanista. As NTCls deveriam apenas nos servir, e não o contrário.

Restam as questões fundamentais: Que tipo de civilização global estamos construindo de fato? Que tipo de civilização deveríamos tentar construir? Então, de que NTCls e ferramentas precisaríamos? Qual o papel de organizações globais como a Unesco?

\section{O papel da Unesco na sociedade da informação}

Para a Unesco, a sociedade da informação representa um desafio e uma oportunidade. O desafio é que a Organização deve encontrar um papel original e inquestionável em um domínio que está agora atingindo a sociedade como um todo, e isso, portanto, interessa a muitas outras organizações. A oportunidade é que os valores e métodos da sociedade da informação darão à Unesco uma chance inigualável para cumprir uma de suas missões fundamentais, como consta em sua Constituição, ou seja, desenvolver a "o intercâmbio desinteressado de idéias e de conhecimento". A estratégia da Unesco pode ser resumida em duas idéias principais:

- Devido à sua missão intelectual e moral, a Unesco se concentra nos aspectos de "conteúdo" da sociedade da informação, incluindo o acesso à informação, treinamento e questões éticas.
- No tocante à infra-estrutura da sociedade da informação, a Unesco se concentra na "info-estrutura" (políticas, redes e aplicações), em lugar da telecomunicação básica e das instalações de informática.

\section{Os aspectos de "conteúdo" dessa estratégia incluem:}

- questões info-éticas (acesso à informação, privacidade, confiabilidade, segurança da informação);

- a observação de políticas de informação nacionais e estruturas legais ou códigos de práticas;

- a promoção do acesso a conteúdos diversificados para os "sem-informação", desenvolvendo um domínio público forte de informação acessível on-line e offline: a "Cibercâmara Global dos Comuns";

- a promoção do pluralismo cultural e lingüístico na sociedade da informação, incluindo o acesso à "Memória Virtual do Mundo";

- promoção de padrões e de cooperação na categorização, identificação e filtragem da informação;

- treinamento na era da informação e no contexto da globalização, com atenção particular às necessidades de profissionais da informação e instrutores (jornalistas, bibliotecários, arquivistas, documentalistas, especialistas em computação), dos usuários (educadores, cientistas, membros de organizações sociais e culturais) e governos;

- participação na cibercultura global, com atenção especial para as necessidades dos jovens;

- finalmente, a presença ativa da Unesco na Web, através dos sites de sua administração central, das unidades de campo e de todas as suas organizações associadas.

\section{Os aspectos de "info-estrutura" des- sa estratégia incluem:}

- apoiar políticas de informação nacionais consistentes (em particular, políticas tarifárias apropriadas nas telecomunicações e as assim chamadas políticas de "acesso universal", em um contexto de "convergência tecnológica", desregulamentação e privatização);

- estabelecer uma rede de pessoas e instituições (com vistas a compartilhar experiências e conhecimentos e a evitar a duplicação de esforços);

- elaborar projetos-piloto inovadores, de aplicação prática: comunidades de aprendizagem virtual, laboratórios virtuais, bibliotecas virtuais, controle on-line, telecentros comunitários com múltiplos propósitos em áreas rurais ou carentes, acesso à informação para pessoas iletradas, interfaces amigáveis para todos:

- melhorar infra-estruturas: bibliotecas públicas, arquivos e centros de documentação, servindo como portais para a sociedade da informação, serviços de informação e redes.

\section{Globalização e abstração}

A sociedade da informação impõe um modelo (cognitivo, eficiente, abstrato, baseado no mercado). Alguns valores alternativos estão surgindo (compartilhamento de conhecimentos, freeware, groupware, novo sentido de cidadania global), mas isso só é possível a partir de uma certa "info-estrutura" e de um nível de educação.

Precisamos definir de um modo muito profundo o que esperamos da emergente civilização global. Isso não deveria ser feito sob a pressão de diferentes globalizações, mas de um ponto de vista mais abrangente, mais sábio. Alguns antropólogos, como André Leroi-Gourhan, definem o "progresso das civilizações" pelo seu nível de abstração. Exemplos clássicos incluem a ferramenta que é uma abstração para a garra ou a mão, e a palavra escrita que é o equivalente abstrato da palavra oral. Se seguirmos essa visão, estaremos realmente dando um grande salto em direção à abstração, quando nos inclinarmos a substituir a realidade pela virtualidade na maioria de nossas atividades. Pode- 
mos, então, ser tentados a pensar que somos uma civilização em desenvolvimento.

A abstração não é um progresso da civilização. É, no máximo, um progresso na instrumentalização da humanidade para servir a objetivos outros que não sejam limitados, não especificados, sem questionamento e não-humanitários. A definição de outro pensador (Teilhard Chardin) é mais esclarecedora. Ele define "progresso" como a capacidade de ir adiante e entender a "diversidade". O principal risco da civilização global é que ela pode terminar limitando a diversidade, impondo normas poderosas de conduta e padrões de comportamento. Se isso acontecesse, não seríamos uma civilização em desenvolvimento.

O estrangeiro é um símbolo inesquecível da diferença. Ele é a imagem do "outro". Mas existem muitos "outros": o desempregado, o pobre ou o iletrado. Eles quase, por natureza, são excluídos da sociedade da informação. Isso por que, mais do que uma sociedade da informação, precisamos de uma sociedade da sabedoria, uma sociedade com sentido, uma sociedade justa em que todos os "outros" podem encontrar o seu lugar.

\section{The information revolution: in search of the common good}

\begin{abstract}
Starting with an analysis of globalization, the author discusses the role of the information society in the building of a global society based on common good. He debates mainly the problem of the telecommunications and their relationship with the market, the need of a regulation for the area, the Internet, the promotion and strength of the public domain, besides issues such as competitiveness and public interest. The role of UNESCO in the information society as well as the search of a humanist meaning for the globalization process are also discussed.
\end{abstract}

\section{Keywords}

Information society; Globalization; Telecommunications.

\section{Em busca de um sentido global}

Precisamos de esperança e de sentido. Como podemos desenvolver atividades não-lucrativas em uma sociedade que reconhece os indivíduos apenas pelo prisma do seu valor de mercado? Como podemos dar algum significado humanista à globalização? Como podemos criar um senso de solidariedade global?

Para os problemas globais, os Estadosnação são muito pequenos para ter qualquer influência decisiva. A Organização das Nações Unidas está longe de ser reconhecida como uma instância de controle global. É um tipo de abstração. Como cidadãos do mundo, sentimos falta de meios de comunicação para criar um espaço comum efetivo, uma ágora pública global, onde pudéssemos discutir e implementar políticas globais. Os únicos agentes verdadeiramente internacionais são os operadores financeiros, os especuladores globais e os operadores de comunicação e de informação global. Mas até mesmo esses não têm em mente nenhum senso real do bem comum global. Eles tendem a maximizar seus próprios interesses específicos. E o único critério de sucesso é o retorno quantitativo do mercado.

Uma vida pública global ainda precisa ser criada. $\mathrm{O}$ que se perdeu na ldade Moderna é o espaço em que a vida pública poderia ser cultivada e desenvolvida. Precisamos urgentemente de um "mundo comum" em oposição a um "mundo global". McLuhan nos falou da "aldeia global". O que precisamos agora é a "casa comum" dessa aldeia.

O bem comum só existe se falarmos, se discutirmos sobre ele, se concordarmos com os outros em uma ação comum sobre o assunto. Nosso mundo globalizado tem realmente um presente comum. Mas sofre da falta de um passado comum e não tem nenhum solo seguro para um futuro comum. Esse mundo compartilha os momentos globais de especulação, dissemina as ferramentas globais da padronização. Mas sofre da falta de qualquer consenso nas suas finalidades fundamentais que parece procurar.

A unidade do gênero humano não pode ser encontrada numa única religião, em uma única filosofia ou mesmo em uma única forma de governo. Deveria ser encontrada no difícil e paradoxal princípio de que a diversidade é, de fato, mais necessária para a unidade do que a própria unidade. A multiplicidade esconde e revela a unidade. Mas, a multiplicidade, como a biodiversidade, é difícil de manter em uma era globalizada. Portanto, a base concreta para uma unidade profunda (possível através da preservação e da atenção à diversidade) é radicalmente ameaçada pela globalização, que impõe sua "unificação" excessivamente simplificada.

Precisamos de uma nova filosofia para a humanidade, cujo conceito central deveria ser a "comunicação". Não no sentido de "comunicação de massa" ou de "tecnologias de informação e de comunicação", mas no sentido de: comunicação das diferenças, comunicação com povos diferentes e comunicação com tudo o que foi pensado em tempos e lugares diferentes. A palavra "comunicação" vem do latim cum (com) e munio (construir paredes fortificadas). Etimologicamente, significa: "construir juntos uma fortificação comum". Isso faz lembrar o preâmbulo da Constituição da Unesco: "Considerando que as guerras começam nas mentes dos homens, está nas mentes dos homens que as defesas de paz devem ser construídas. $O$ desconhecimento dos modos de vida de cada um tem sido a causa comum de suspeita e desconfiança entre os povos do mundo". A comunicação deveria ser vista como um método e uma filosofia para construir as "defesas de paz". Mas não esqueçamos jamais que as tecnologias de "comunicação" não garantem a "comunicação". Elas são apenas meios, e não têm nenhum significado.

\section{REFERÊNCIA BIBLIOGRÁFICA}

1. XAVIER, Patrick. Price setting and regulation for telecommunications in the absence of reliable and detailed cost information. Telecommunications Policy, v. 21, n. 3, p. 213-33, 1997.

\section{Philippe Quéau}

Diretor da Divisão de Informação e Informática, Organização das Nações Unidas para a Educação, Ciência e Cultura (Unesco).

p.queau@unesco.org

Tradução do inglês de Irati Antonio. 